(6) OPEN ACCESS

\title{
Desmoplastic fibroblastoma of the left upper arm
}

\author{
Reetu Grewal, ${ }^{1}$ Patrick Natter, ${ }^{2}$ Raafat Makary, ${ }^{3}$ Julia Silliman ${ }^{4}$
}

\begin{abstract}
${ }^{1}$ Community Health and Family Medicine, University of Florida Colege of Medicine Jacksonville, Jacksonville, Florida, USA 2Department of Radiology, University of Florida Colege of Medicine Jacksonville, Jacksonville, Florida, USA ${ }^{3}$ Department of Pathology, University of Florida Health Science Center Jacksonville, Jacksonville, Florida, USA ${ }^{4}$ Department of Biology, University of Florida, Gainesville, Florida, USA
\end{abstract}

\section{Correspondence to} Dr Reetu Grewal, reetu.grewal@jax.ufl.edu

Accepted 9 January 2018

Check for updates

To cite: Grewal $R$, Natter $P$, Makary R, et al. BMJ Case Rep Published Online First: [please include Day Month Year]. doi:10.1136/bcr-2017221738

\section{SUMMARY}

An elderly female patient presented to the clinic with a several-week history of a mass in her left upper arm that was tender to the touch. The mass was initially thought to be a schwannoma of the left radial nerve based on imaging and was surgically removed. The pathology report revealed an uncommon diagnosis of desmoplastic fibroblastoma.

\section{BACKGROUND}

The differential diagnosis of soft-tissue masses in the extremities is extensive, and imaging is often helpful in determining the aetiology of such masses, with histological characteristics giving a definitive diagnosis. This case highlights an uncommon diagnosis, which was not suspected based on initial imaging.

\section{CASE PRESENTATION}

A 70-year-old otherwise healthy woman presented with a 1-month history of a left upper arm mass that started small and grew over the past several weeks. She denied having any heavy lifting, history of overuse or injury to the area. She was not on any blood thinners, noticed that the mass was tender to the touch and had occasional tingling into the left hand. There was no weakness of the left arm or hand.

On examination, there was a visible and palpable mass near the posterolateral distal humerus, which was firm and somewhat mobile within the triceps muscle. The mass measured approximately $4.5 \times 2.4 \mathrm{~cm}$ and was sensitive to the touch; however, there was no warmth or skin discolouration noted. Full range of motion at the left shoulder and elbow was demonstrated without pain, and sensation was grossly intact for the left upper extremity. Radial pulse was $2+$ on the left side, with capillary refill less than $1 \mathrm{~s}$, and no epicondylar, axillary, cervical or supraclavicular lymphadenopathy was noted on the left side.

The patient underwent an MRI with and without contrast of the left upper arm, revealing a fusiform-shaped, enhancing mass that was in direct contact with the lateral cortex of the mid humerus, followed the course of the radial nerve. The patient also had a preoperative evaluation by neurology whose examination demonstrated cranial nerves $2-12$ to be intact with $5 / 5$ motor strength throughout. Sensory examination was normal to pinprick, touch and position. The patient demonstrated generalised hyporeflexia. There was no clonus, Babinski sign or Hoffmann sign.
Cerebellar examination and gait was normal. There was also a normal range of movement. Based on the normal clinical examination findings, nerve conduction study was not performed. After consultation with an orthopaedic oncologist, the patient decided to have surgery to remove what appeared to be a nerve sheath tumour, such as a schwannoma, based on clinical presentation and imaging findings. During surgery, it was noted that the tumour was located just under the brachioradialis muscle, had displaced the majority of the radial nerve and was also adherent to the humerus.

\section{INVESTIGATIONS Imaging}

MRI imaging for our patient demonstrated a well-circumscribed mass which was T2 and T1 hypointense (figures 1-3). On short tau inversion recovery (STIR) imaging, which is a fluid-sensitive sequence, there was hypointensity with small internal somewhat linear areas of hyperintensity (figure 4). On T1-weighted fat-saturated postcontrast imaging, the mass heterogeneously enhanced internally and also demonstrated peripheral rim enhancement (figure 5).

\section{Pathology}

The tumour was resected and sent for pathological analysis. The received specimen was labelled as 'left radial nerve schwannoma' and consisted of a $4.5 \times 1.5 \times 1.5 \mathrm{~cm}$ cylindrical portion of white-tan tissue with attached brown muscle tissue. The cut surface was also solid white and otherwise grossly unremarkable. The specimen was entirely submitted.

Microscopic examination revealed a hypocellular neoplasm with spindle to ovoid nuclei in dense fibrosclerotic stroma. The lesion was well circumscribed with no infiltrative border, necrosis, mitosis or significant cellular atypia (figures 6 and 7). Immunostain was focally positive for desmin (figure 8) with weak equivocal S100 staining in rare cells. The following immunostains were negative: epithelial membrane antigen (for perineurioma), CD34 (for solitary fibrous tumour), smooth muscle actin (for muscle lineage) and MUC 4 (for sclerosing epithelioid fibrosarcoma). These features were negative for a nerve sheath tumour and most consistent with a desmoplastic fibroblastoma.

\section{DIFFERENTIAL DIAGNOSIS}

The differential diagnosis for upper extremity soft-tissue masses is quite broad and includes ruptured muscle tendon, fibroma of tendon 


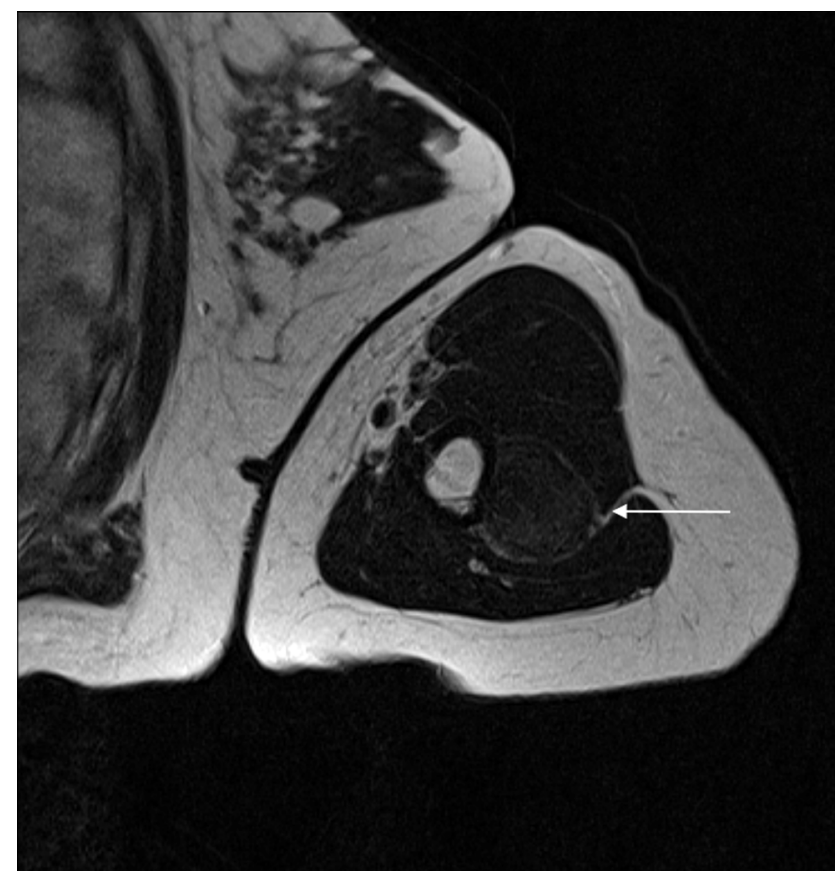

Figure 1 Axial T2-weighted MRI image demonstrates a wellcircumscribed mass (arrow) in the left upper arm which is T2 hypointense and is adjacent to the humerus.

sheath, mesenchymal tumours (including lipomas, angiomas, nerve sheath tumours and sarcomas), skin appendage lesions (epidermal cysts and pilomatricoma) and inflammatory lesions (fasciitis and abscess). ${ }^{1}$ Typically, these masses can be identified using clinical characteristics, with imaging studies providing further evaluation, and histological evaluation when needed.

Desmoplastic fibroblastoma, occurs in the subcutaneous and intramuscular tissues, is similar to a desmoid tumour, which is a tumour of the connective tissue, and the two are differentiated by

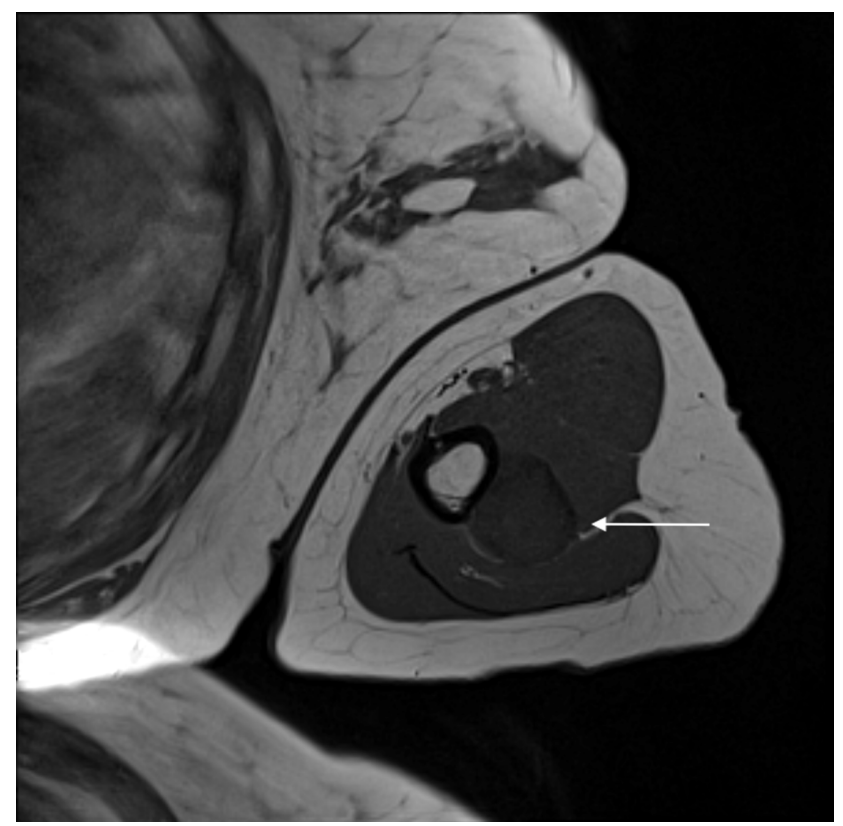

Figure 2 Axial T1-weighted MRI image demonstrates a wellcircumscribed mass (arrow) in the left upper arm which is T1 hypointense and is adjacent to the humerus.

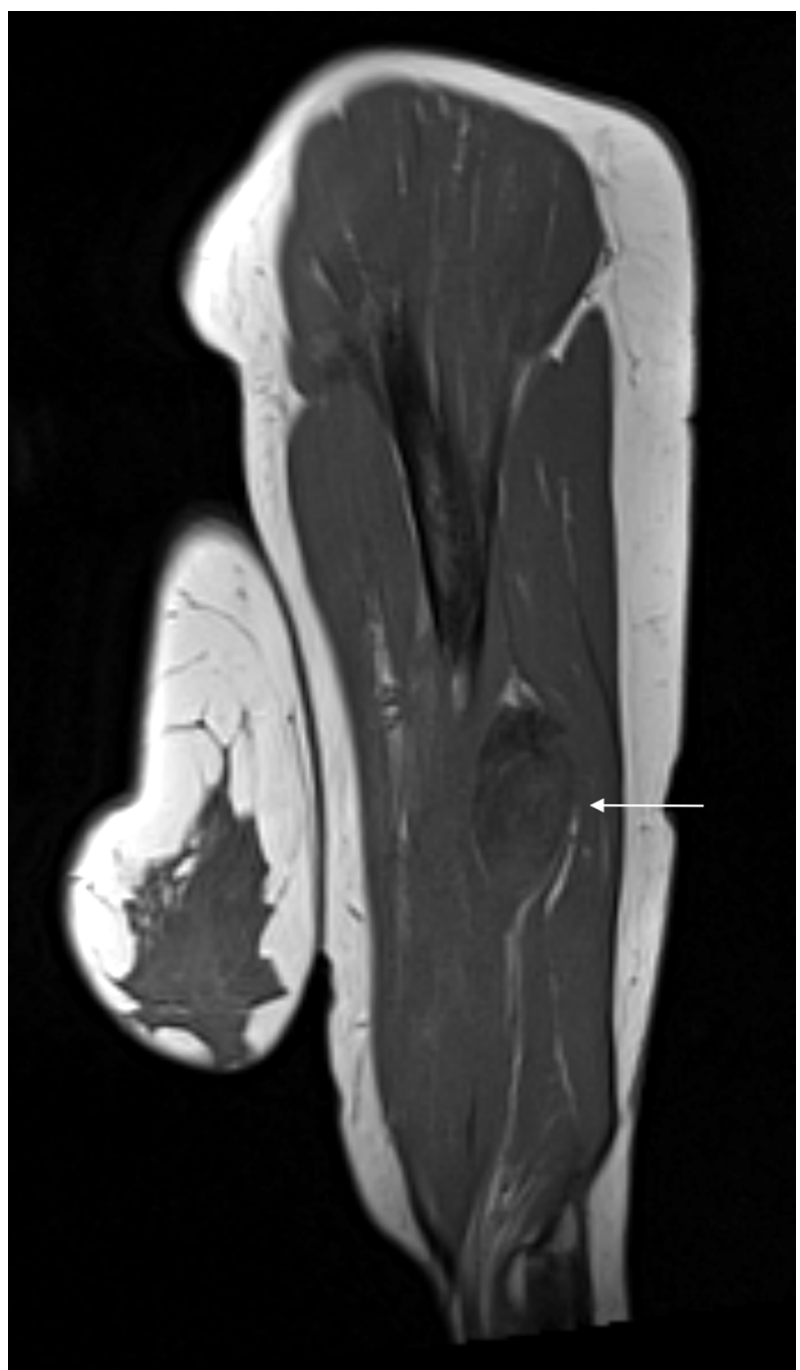

Figure 3 Sagittal T1-weighted MRI image demonstrates a wellcircumscribed mass (arrow) in the left upper arm just adjacent to the midhumerus with $\mathrm{T} 1$ hypointensity.

histological features and cytogenetic analysis. Desmoid tumours involve more aggressive invasion of surrounding tissues than desmoplastic fibroblastomas and can recur. ${ }^{1}$

\section{TREATMENT}

The patient underwent a complete resection of the mass, followed by a course of physical therapy.

\section{OUTCOME AND FOLLOW-UP}

The patient has done well 1 year postoperatively. She has retained full strength and sensation of her left upper extremity, and follow-up imaging performed 6 months and 1 year postoperatively revealed no recurrence of the tumour.

\section{DISCUSSION}

Desmoplastic fibroblastoma is an uncommon slow-growing benign tumour, also known as a collagenous fibroma, and occur in the subcutaneous or intramuscular tissues. ${ }^{23}$ These tumours are generally small, superficial, well circumscribed and located typically in the upper extremities, upper back and lower extremities. ${ }^{4}$ These tumours occur in adults more often in men, and once excised, these tumours rarely recur. ${ }^{2-4}$ 


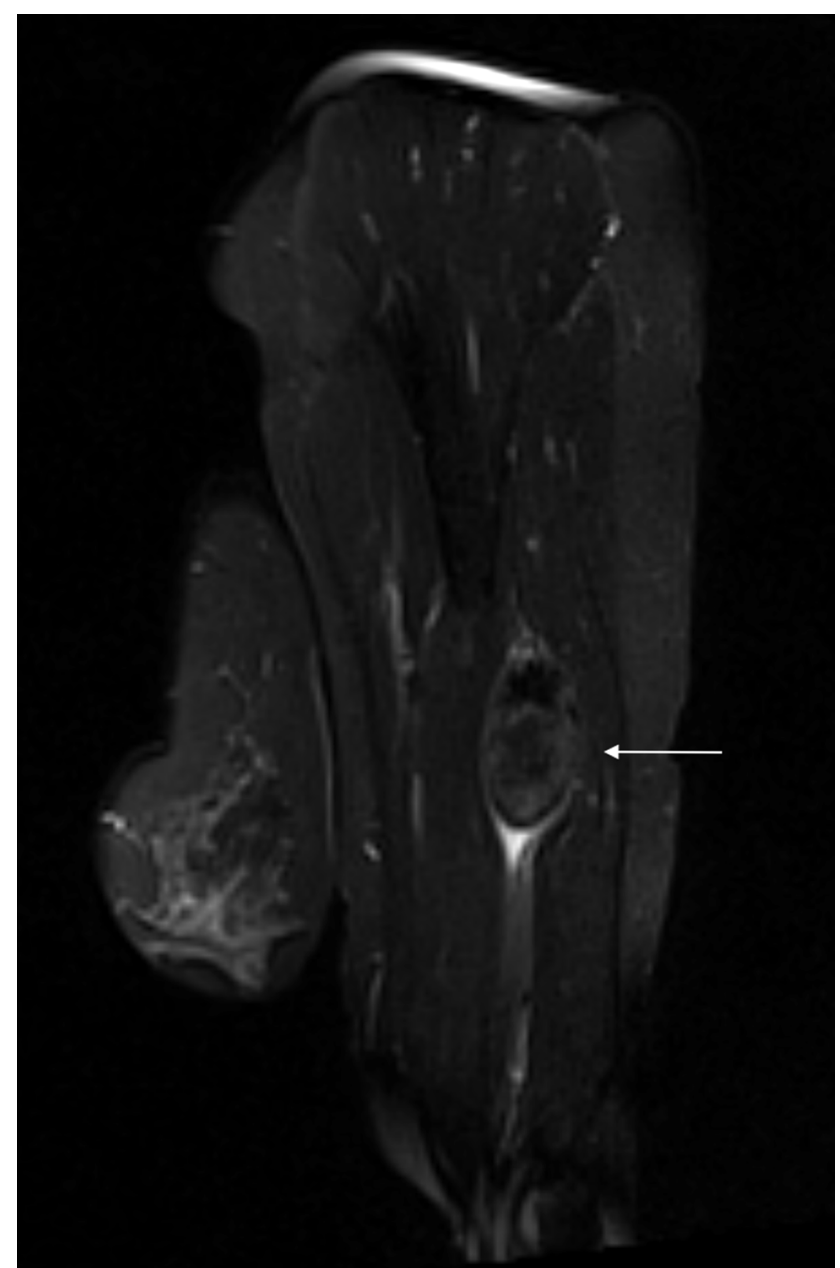

Figure 4 Sagittal STIR MRI image demonstrates a well-circumscribed mass (arrow) in the left upper arm just adjacent to the humerus with overall hypointensity with a few small somewhat linear areas of internal hyperintensity. STIR, short T1 inversion recovery.

The MRI appearance of a desmoplastic fibroblastoma is variable but typically shows a well-circumscribed and heterogeneous mass. ${ }^{5}$ On T1-weighted precontrast images, the tumour varies from T1 hypointensity to intermediate signal, and on T2-weighted images, the signal varies from T2 hypointensity to hyperintensity sometimes with mixed hypointensity and hyperintensity. ${ }^{5-10}$ On T1-weighted postcontrast images, heterogeneous internal enhancement with peripheral rim enhancement is also reported. ${ }^{5-10}$ Many soft-tissue masses have hyperintensity on T2-weighted images and desmoplastic fibroblastoma can have T2 hypointense signal due to its low cellularity and abundant collagen. ${ }^{10}$ However several other soft-tissue masses also have low T2 signal particularly other masses with low cellularity, abundant collagen and/or calcification including other fibrous tumours or calcified masses. ${ }^{10}$ Due to the variable appearance, imaging is not diagnostic of desmoplastic fibroblastoma and pathological analysis is necessary for more definitive diagnosis.

Fibroma of tendon sheath and desmoplastic fibroblastoma have established clinical and histological criteria; however in certain cases, there can be clinical and histological overlap making differentiation difficult. ${ }^{11}$ Most fibroma of tendon sheath are in the hands or feet with clinical, radiographic and intraoperative relation/attachment to the tendon structure. Fibroma of tendon sheath tend to be multinodular and cellular with moderate

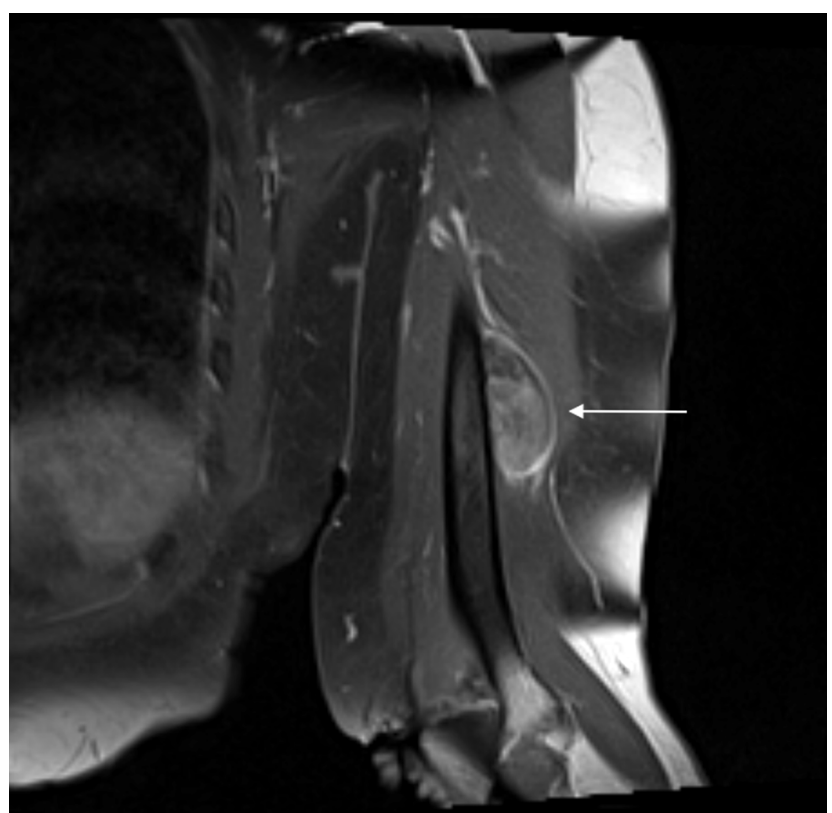

Figure 5 Coronal fat-saturated T1 postcontrast MRI image demonstrates a well-circumscribed mass (arrow) in the left upper arm adjacent to the humerus which demonstrates heterogeneous internal enhancement with peripheral rim enhancement.

vascularity. This is unlike the widespread distribution including acral sites, hypocellularity and hypovascularity of desmoplastic fibroblastoma. However, this distinction becomes difficult when a hypocellular fibroma of tendon sheath arises in acral sites tendon or aponeurosis. Also, overlapping chromosomal

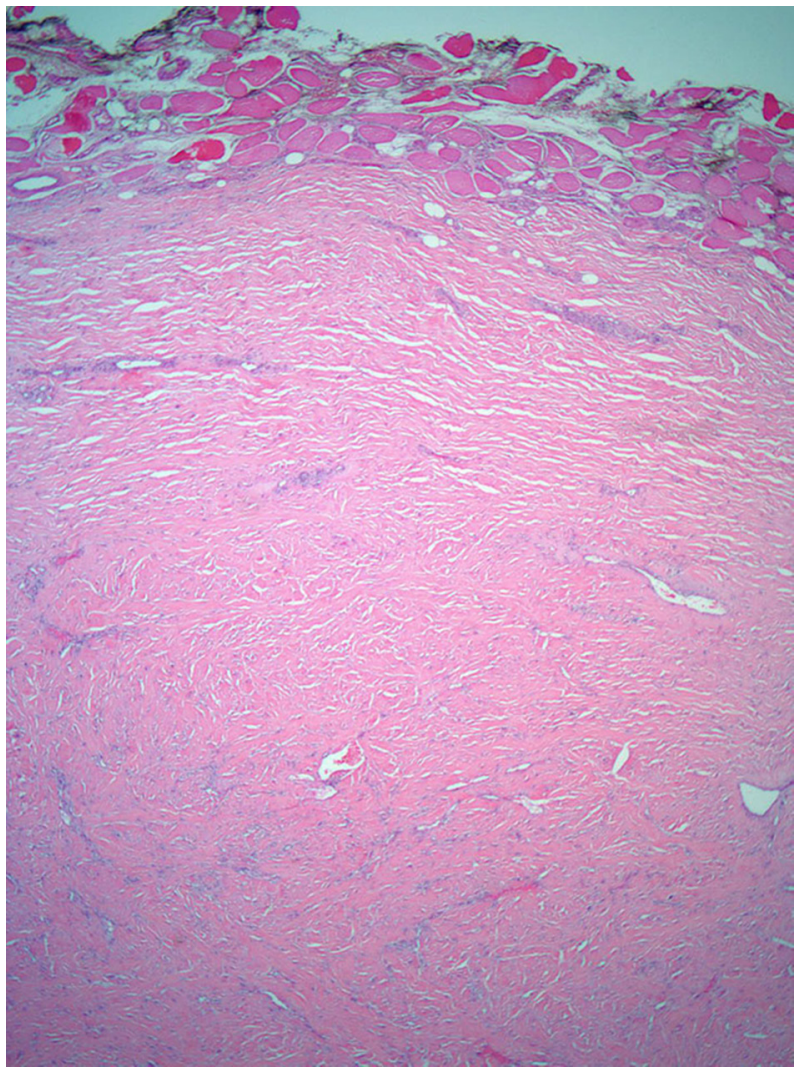

Figure 6 A well-circumscribed hypocellular neoplasm is demonstrated $(H \& E \times 2)$. 


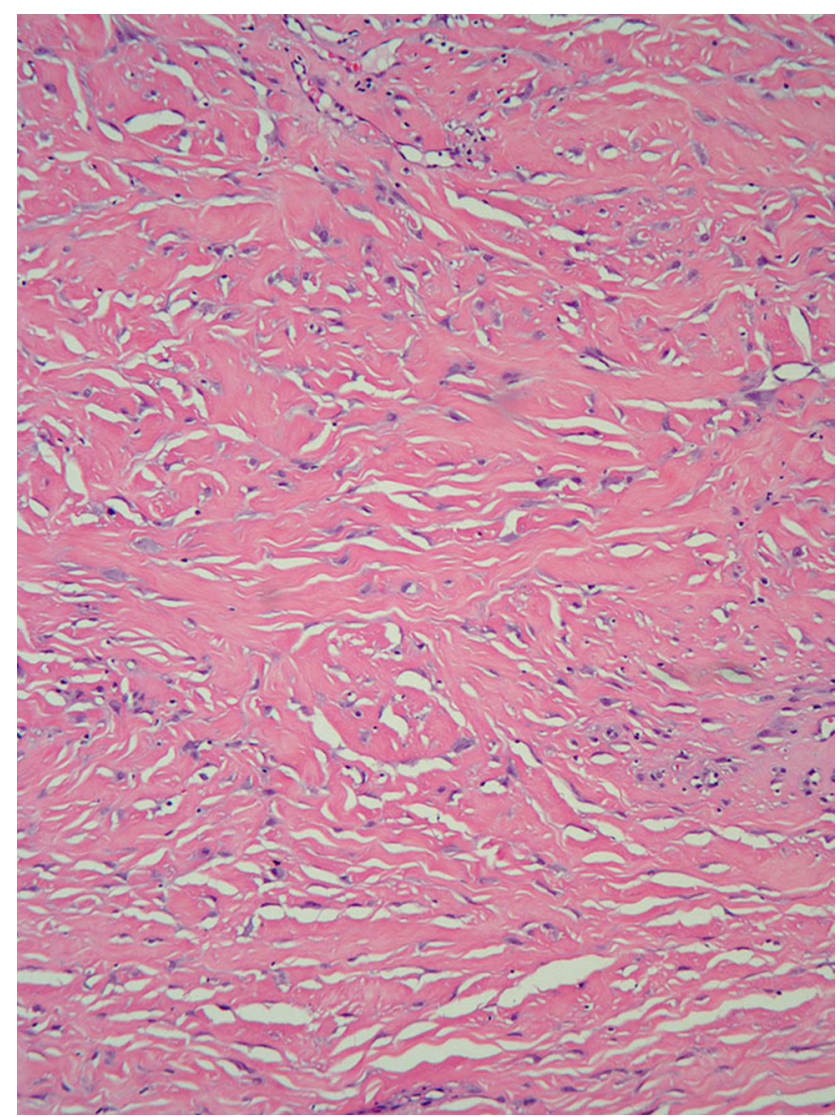

Figure 7 Hypocellular neoplasm with spindle to ovoid nuclei in dense fibrosclerotic stroma, with no infiltrative border, necrosis, mitosis or significant cellular atypia $(\mathrm{H} \& \mathrm{E} \times 10)$.

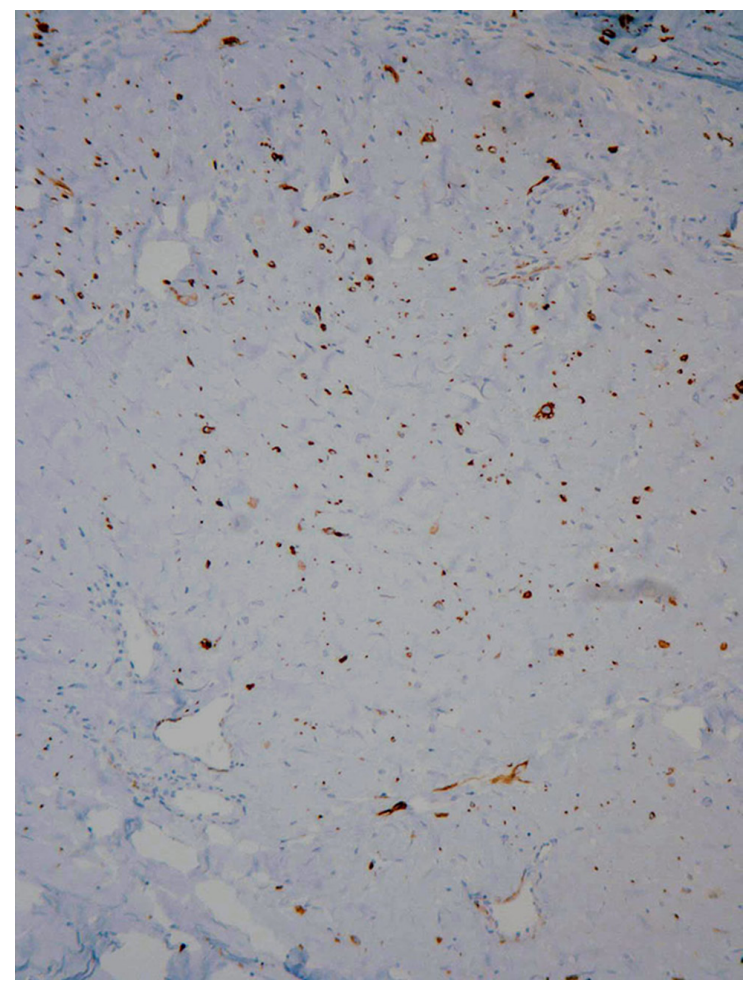

Figure 8 Immunostain was focally positive for desmin with weak equivocal $\$ 100$ staining in rare cells.

\section{Patient's perspective}

I really didn't know what was going on with my arm when it first started. I had a small bump that kept getting bigger. I was relieved when the doctor told me he thought it was not a dangerous cancer, but I was afraid to have surgery done because he said I might not be able to use my left arm after the surgery. He said I could get weak or lose the feeling in my arm or hand, and that scared me. After talking with my husband, I decided to have the surgery done because I was already having some funny feelings in my left hand. I remember waking up after the surgery and immediately trying to lift my arm and open and close my hand. I said 'Thank God' when I was able to do it! I did physical therapy for a few weeks and now my hand and arm work just fine. The scar is small, and I am relieved that the growth wasn't anything that would harm me now that it's out. I feel good after hearing that the follow-up MRIs showed they got it all, and it's not coming back. I am glad I decided to have the surgery, I can go about my life without any problem now.

\section{Learning points}

- The differential of upper extremity masses is extensive but typically can be differentiated by clinical, imaging and/or histological features.

- Due to the extensive differential for upper extremity masses, it is important to determine the aetiology of the mass due to the broad differences in treatment and prognosis.

- Desmoplastic fibroblastoma is a rare benign tumour that is amenable to resection and unlikely to recur.

rearrangement in $11 \mathrm{q} 12$ and translocation $(2 ; 11)$ are reported in desmoplastic fibroblastoma and fibroma of tendon sheath although more reported in desmoplastic fibroblastoma. Recently, increased mRNA expression of FOSL1 was considered a reliable diagnostic aid in differentiating desmoplastic fibroblastoma from fibroma of tendon sheath and other mimics. FOSL1 encodes a nuclear leucine zipper protein involved in the proliferation and differentiation of tumour cells. The FOSL1 gene locus at 11q13 is in close proximity to $11 \mathrm{q} 12$ and considered as the culprit gene involved in $11 \mathrm{q} 12$ rearrangement characteristic for desmoplastic fibroblastoma. FOSL1 expression can be evaluated by immunohistochemistry or chromogenic in situ hybridisation on formalin-fixed paraffin-embedded sections. ${ }^{11}$ Expression of FOSL1 was not performed in our case due to the difficult availability and cost-effectiveness of anti-FOSL1 primary antibody. Specifically in our case, cytogenetic testing was not performed since the tumour was completely excised, and the distinction between desmoplastic fibroblastoma and fibroma of tendon sheath could be made from histology alone and because a cytogenetic study would not change the management plan.

Contributors RG is responsible for entire manuscript. PN prepared radiology images and discussion on imaging. RM prepared pathology images and discussion on pathology. JS provided assistance with case write-up, obtaining patient consent and perspective and editing of manuscript.

Competing interests None declared.

Patient consent Obtained.

Provenance and peer review Not commissioned; externally peer reviewed.

Open Access This is an Open Access article distributed in accordance with the Creative Commons Attribution Non Commercial (CC BY-NC 4.0) license, which 
permits others to distribute, remix, adapt, build upon this work non-commercially, and license their derivative works on different terms, provided the original work is properly cited and the use is non-commercial. See: http://creativecommons.org/ licenses/by-nc/4.0/

(C) BMJ Publishing Group Ltd (unless otherwise stated in the text of the article) 2018. All rights reserved. No commercial use is permitted unless otherwise expressly granted.

\section{REFERENCES}

1 Beaman FD, Kransdorf MJ, Andrews TR, et al. Superficial soft-tissue masses: analysis, diagnosis, and differential considerations. Radiographics 2007;27:509-23.

2. Merriman DJ, Deavers MT, Czerniak BA, et al. Massive desmoplastic fibroblastoma with scapular invasion. Orthopedics 2010;33.

3 Evans HL. Desmoplastic fibroblastoma. A report of seven cases. Am J Surg Pathol 1995; 19:1077-81.

4 Nielsen GP, O'Connell JX, Dickersin GR, et al. Collagenous fibroma (desmoplastic fibroblastoma): a report of seven cases. Mod Pathol 1996;9:781-5.
5 Miettinen M, Fetsch JF. Collagenous fibroma (desmoplastic fibroblastoma): a clinicopathologic analysis of 63 cases of a distinctive soft tissue lesion with stellateshaped fibroblasts. Hum Pathol 1998;29:676-82.

6 Shuto R, Kiyosue H, Hori Y, et al. CT and MR imaging of desmoplastic fibroblastoma. Eur Radiol 2002;12:2474-6.

7 Bonardi M, Zaffarana VG, Precerutti M. US and MRI appearance of a collagenous fibroma (desmoplastic fibroblastoma) of the shoulder. J Ultrasound 2014;17:53-6.

8 Kamata Y, Anazawa U, Morioka H, et al. Natural evolution of desmoplastic fibroblastoma on magnetic resonance imaging: a case report. J Med Case Rep 2011:5:139.

9 Yamamoto A, Abe S, Imamura T, et al. Three cases of collagenous fibroma with rim enhancement on postcontrast T1-weighted images with fat suppression. Skeletal Radiol 2013;42:141-6.

10 Walker KR, Bui-Mansfield LT, Gering SA, et al. Collagenous fibroma (desmoplastic fibroblastoma) of the shoulder. AJR Am J Roentgenol 2004;183:1766.

11 Kato I, Yoshida A, Ikegami M, et al. FOSL1 immunohistochemistry clarifies the distinction between desmoplastic fibroblastoma and fibroma of tendon sheath. Histopathology 2016;69:1012-20.

Copyright 2017 BMJ Publishing Group. All rights reserved. For permission to reuse any of this content visit http://group.bmj.com/group/rights-licensing/permissions.

BMJ Case Report Fellows may re-use this article for personal use and teaching without any further permission.

Become a Fellow of BMJ Case Reports today and you can:

- Submit as many cases as you like

- Enjoy fast sympathetic peer review and rapid publication of accepted articles

- Access all the published articles

Re-use any of the published material for personal use and teaching without further permission

For information on Institutional Fellowships contact consortiasales@bmjgroup.com

Visit casereports.bmj.com for more articles like this and to become a Fellow 